\title{
Diphyllobothrium latum Mimicking Subacute Appendicitis
}

\author{
Konika Sharma $^{\mathrm{a}, \mathrm{c}}$, Karn Wijarnpreecha ${ }^{\mathrm{a}}$, Nancy Merrella, b
}

\begin{abstract}
Diphyllobothrium latum (D. latum) infection in humans is uncommon in the United States. Although there has been a drastic decline in the report of $D$. latum infection in this region, physicians should be aware of an uncommon presentation and its clinical relevance. We report a case of 55-year-old female of Ecuadorian/Peruvian origin who presented with an unknown cause of chronic right lower quadrant abdominal pain for 2 months without other particular symptoms. Initial workup revealed evidence of iron deficiency anemia, and stool occult blood test was positive. She was scheduled for a colonoscopy to assess the source of occult gastrointestinal bleeding. During her bowel preparation, she passed a $25 \mathrm{~cm}$ long white tapeworm-like material confirmed microscopically. Despite passing a worm she continued to have abdominal pain. During the colonoscopy, another worm was found lodged in the appendiceal orifice. The colonoscopic images revealed a segmented tapeworm showing contractile motility, approximately $12 \mathrm{~cm}$ in length and $6 \mathrm{~mm}$ wide in the appendiceal orifice. The scope was unsuccessful in removing the worm. The parasitological and microbiological examination of the passed worm was positive for D. latum. D. latum a fish tapeworm that infects humans after the ingestion of raw or undercooked fish. The patient had a history of often eating lightly marinated raw fish ("ceviche") in Peru several months before presentation. It is uncommon for $D$. latum infection to present with iron deficiency anemia. As the worm absorbs approximately $80 \%$ of dietary vitamin $\mathrm{B} 12$, prolonged $D$. latum infection usually causes vitamin B12 deficiency and megaloblastic anemia, which is reported to affect about $40 \%$ of cases. Abdominal pain related to mechanical obstruction is reported, but this case is unique in that the worm preferentially attached to the appendiceal orifice causing subacute focal appendiceal pain. She was treated with a single dose of oral praziquantel. After the treatment, she developed minor cramping for the next 2 days which resolved by day 3 , and recalled passing half-inch sized pieces of white tissue and subsequently improved. Although $D$. latum infection is an uncommon cause of chronic abdominal pain with iron deficiency anemia, it is crucial to consider because of the potentially treatable outcome.
\end{abstract}

Manuscript submitted February 3, 2018, accepted April 23, 2018

aDepartment of Internal Medicine, Bassett Medical Center, Cooperstown, NY, USA

bDivision of Digestive Disease, Bassett Medical Center, Cooperstown, NY, USA

${ }^{\mathrm{c} C o r r e s p o n d i n g ~ A u t h o r: ~ K o n i k a ~ S h a r m a, ~ D e p a r t m e n t ~ o f ~ I n t e r n a l ~ M e d i c i n e, ~}$ Bassett Medical Center, One Atwell Road, Cooperstown, NY 13326, USA. Email: drkonika@gmail.com

doi: https://doi.org/10.14740/gr989w
Keywords: Diphyllobothrium latum; Diphyllobothriosis; Iron deficiency anemia

\section{Introduction}

Diphyllobothrium latum (D. latum) is one of the longest intestinal tapeworms that infects humans [1]. The recent epidemiologic study reported that approximately 20 million people are infected worldwide and tend to have endemicity in areas where consumption of raw fish is popular (Scandinavia, Northern Europe, Russia, Japan) [2]. The Centers for Disease Control and Prevention estimated that up to 200 cases occurred during 1977 to 1981, but the prevalence has declined over the last 100 years [3]. The first case of D. latum infection in the United States was reported in a child born in Minnesota [4]. Humans are infected by ingesting larvae in raw or poorly cooked freshwater fish acting as a second intermediate host harboring the infective forms. Despite the large size, many D. latum infections are reported to be asymptomatic [5]. Twenty-five percent can present with diarrhea, abdominal pain, recurrent abdominal pain, fatigue, headache, constipation or pernicious anemia $[6,7]$. We present an interesting case diagnosed with $D$. latum infection with an unusual presentation of chronic right lower abdominal pain mimicking subacute appendicitis.

\section{Case Report}

A 55-year-old female of Ecuadorian/Peruvian origin presented with an unknown cause of chronic right lower quadrant abdominal pain for 2 months. She denied diarrhea, nausea, vomiting, fever, or other particular symptoms. She had no significant medical or family history. Except for mild pallor and tenderness in right-lower quadrant area of the abdomen, no pertinent findings were found from physical examination. Laboratory evaluation revealed mild anemia from iron deficiency (low serum iron $41 \mu \mathrm{g} / \mathrm{dL}$, low iron saturation $11 \%$, total iron binding capacity $382 \mu \mathrm{g} / \mathrm{dL}$, and decreased mean corpuscular volume $62.9 \mathrm{fL}$ ). Vitamin B12 and folate values were in the normal range. A gynecological cause of anemia was excluded. A fecal occult blood test was positive. The patient was scheduled for a colonoscopy to assess the source of occult gastrointestinal bleeding. During her bowel preparation, she passed a $25 \mathrm{~cm}$ long white tapeworm-like material. Despite passing the worm she continued to have focal right lower abdominal pain. Colonoscopy documented another worm approximately $12 \mathrm{~cm}$ 


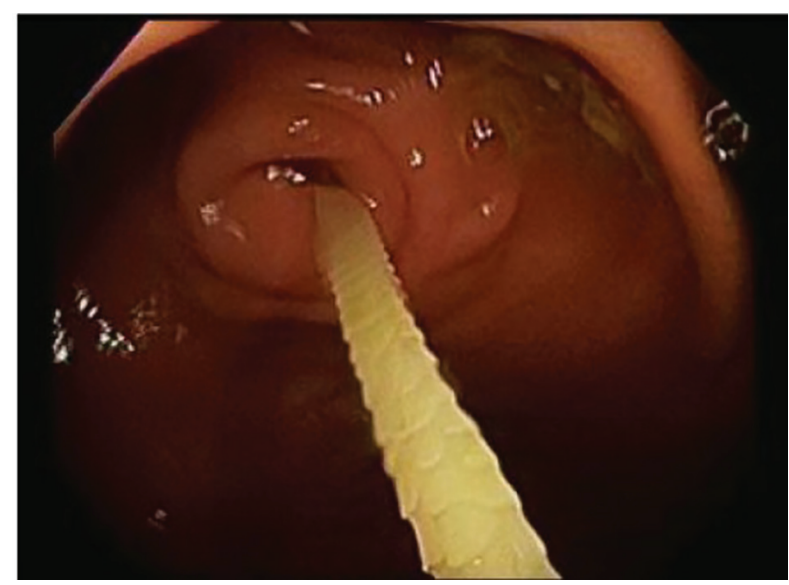

Figure 1. A segmented tapeworm showing contractile motility in the appendiceal orifice.

in length, $6 \mathrm{~mm}$ wide was found lodged in the appendiceal orifice as shown in Figures 1 and 2. Attempts at gentle snare extraction were unsuccessful. Parasitological and microbiological examination confirmed that the first passed worm was positive for $D$. latum. The patient had a history of eating raw fish in Peru called "ceviche" (pieces of raw fish freshly marinated in lemon and salt) several months before presentation. She was treated with a single dose of $600 \mathrm{mg}$ oral praziquantel. After the treatment, she developed minor cramping for the next 2 days which resolved by day 3 , and recalled passing halfinch sized pieces of white tissue and subsequently improved. No eggs were seen in the stool samples checked in 3 months later. She has no residual abdominal pain.

\section{Discussion}

The colonoscopic images revealed a segmented tapeworm showing contractile motility, approximately $12 \mathrm{~cm}$ long, 6 $\mathrm{mm}$ wide, attached inside the appendix. Mature $D$. latum can reach a maximum length of up to $25 \mathrm{~m}$ [1] consisting of a large number of segments called proglottids which are rectangular in shape, 3 - $5 \mathrm{~mm}$ long and $9-12 \mathrm{~mm}$ wide. D. latum infection can be caused by the ingestion of raw and undercooked fish. Humans are the main definitive host for $D$. latum. Most infected cases are asymptomatic, and about $40 \%$ may have vitamin B12 deficiency, but only $2 \%$ progress to anemia [8]. Prolonged D. latum infection usually causes vitamin B12 deficiency and megaloblastic anemia by parasite-mediated dissociation of the vitamin B12-intrinsic factor complex in the gut lumen making B12 unavailable to the host [9]. This can cause neurological damage to the host including central nervous system degenerative and peripheral neuropathy. Adult tapeworms are easily treated with praziquantel. A single dose of $25 \mathrm{mg} / \mathrm{kg}$ is highly effective against $D$. latum infection in humans [10]. The best prophylaxis is to avoid the consumption of raw or undercooked fish. It is uncommon of D. latum infection in humans, to present with chronic abdominal pain with iron deficiency anemia, especially in a non-endemic area as in this case. Physicians should be aware of this uncommon presentation, and

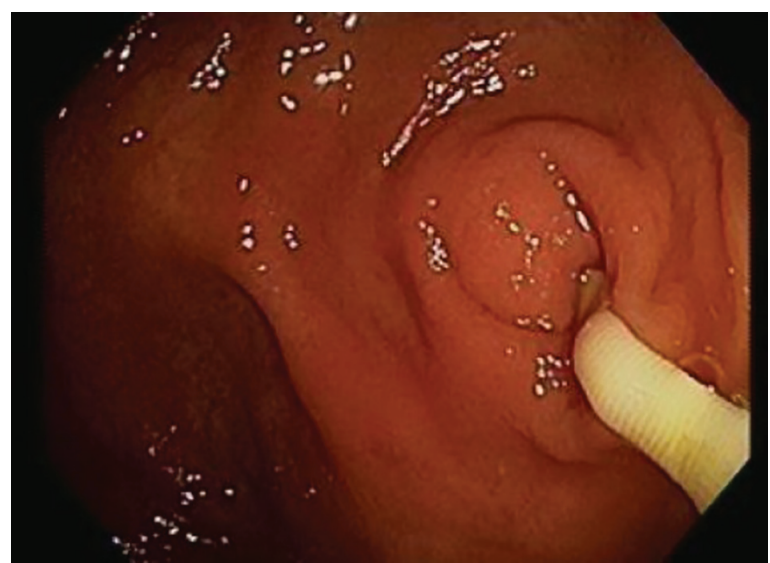

Figure 2. A segmented tapeworm.

meticulous history-taking, including recent travel and raw fish ingestion, are important clues leading to early diagnosis and treatment. In addition, since it may be found accidentally during colonoscopy, endoscopists should recognize the parasite and its treatment.

We present a case of an uncommon presentation of $D$. latum infection in humans with a chronic unknown cause of abdominal pain and anemia. Even though it rarely occurs, awareness of $D$. latum manifestation which leads to early diagnosis and treatment should be accentuated to the physician. Treatment does not seem to represent a serious problem, unlike a low awareness of the infection risk when eating raw or undercooked fish. Better education for populations, particularly in the regions under potential risk of infection, is necessary [11].

\section{Funding}

None.

\section{Conflict of Interest}

We do not have any financial or non-financial potential conflict of interest.

\section{Author Contributions}

Sharma K: acquisition of data, drafting the articles, final approval; Wijarnpreecha K: acquisition of data, drafting the articles, interpretation of the data, final approval; Merrell N: conception and critical revision, final approval.

\section{References}

1. Scholz T, Garcia HH, Kuchta R, Wicht B. Update on the human broad tapeworm (genus diphyllobothrium), including clinical relevance. Clin Microbiol Rev. 2009;22(1):146-160, Table of Contents. 
2. Chai JY, Darwin Murrell K, Lymbery AJ. Fish-borne parasitic zoonoses: status and issues. Int J Parasitol. 2005;35(11-12):1233-1254.

3. Dick TA, Nelson PA, Choudhury A. Diphyllobothriasis: update on human cases, foci, patterns and sources of human infections and future considerations. Southeast Asian J Trop Med Public Health. 2001;32(Suppl 2):5976.

4. Nickerson WS. The broad tapeworm in Minnesota, with the report of a case of infection acquired in the state. JAMA. 1906;46:711-713.

5. Nakamura-Uchiyama F, Hiromatsu K, Ishiwata K, Sakamoto Y, Nawa Y. The current status of parasitic diseases in Japan. Intern Med. 2003;42(3):222-236.

6. Lee SH, Park H, Yu ST. Diphyllobothrium latum infection in a child with recurrent abdominal pain. Korean J Pedi- atr. 2015;58(11):451-453.

7. Von Bonsdorff B. Pernicious anemia caused by Diphyllobothrium latum, in the light of recent investigations. Blood. 1948;3(1):91-102.

8. Schantz PM. Tapeworms (cestodiasis). Gastroenterol Clin North Am. 1996;25(3):637-653.

9. Vuylsteke P, Bertrand C, Verhoef GE, Vandenberghe P. Case of megaloblastic anemia caused by intestinal taeniasis. Ann Hematol. 2004;83(7):487-488.

10. Groll E. Praziquantel for cestode infections in man. Acta Trop. 1980;37(3):293-296.

11. Tavares LE, Luque JL, do Bomfim TC. Human diphyllobothriasis: reports from Rio de Janeiro, Brazil. Revista brasileira de parasitologia veterinaria $=$ Brazilian Journal of Veterinary Parasitology: Orgao Oficial do Colegio Brasileiro de Parasitologia Veterinaria. 2005;14(2):85-87. 